\title{
Somatic sex determination ${ }^{*}$
}

\author{
David Zarkower ${ }^{\S}$, Department of Genetics, Cell Biology, and \\ Development, University of Minnesota, Minneapolis, MN 55455 USA
}

\section{Table of Contents}

1. A global sex determination pathway controls sexual dimorphism ............................................ 2

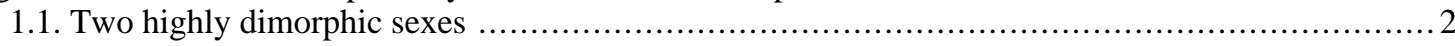

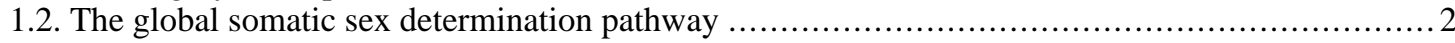

2. The balance of X-linked and autosomal signal elements controls $x o l-1$................................ 3

3. Sex determination and dosage compensation are coordinately regulated .............................. 4

3.1. The SDC proteins connect sex determination and dosage compensation ............................. 4

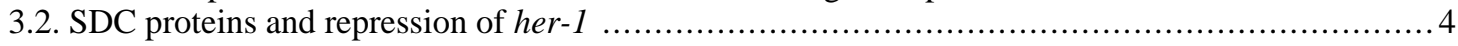

4. HER-1 and TRA-2 provide cell non-autonomous control of sexual fate .................................. 4

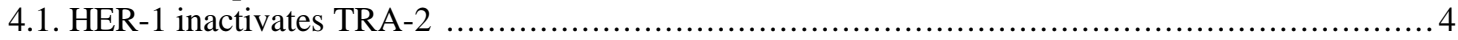

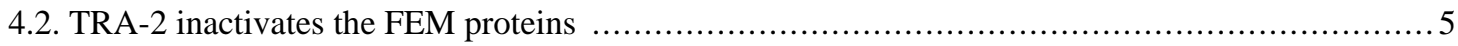

5. High versus low $\mathrm{ra}-\mathrm{l}$ activity determines somatic cell sexual fates ........................................ 6

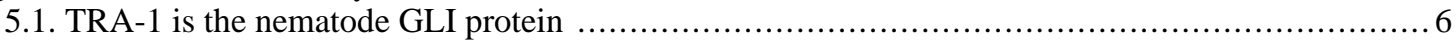

5.2. $\mathrm{tra}-\mathrm{l}$ has distinct functions in sex determination and gonadogenesis .............................. 6

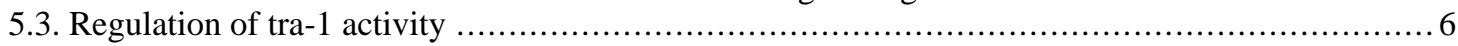

6. TRA-1 links global and tissue-specific sexual regulation ................................................. 6

7. Downstream sexual regulators: the interface between sex determination and sexual differentiation .......... 7

8. Some aspects of sex determination may be evolutionarily conserved ..................................... 7

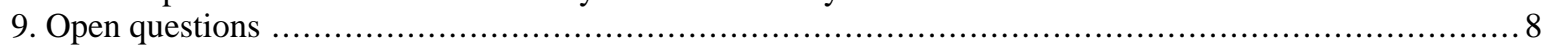

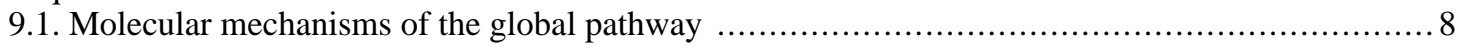

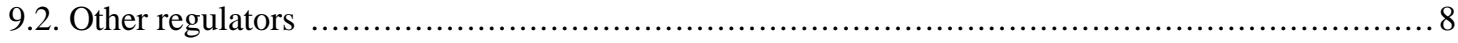

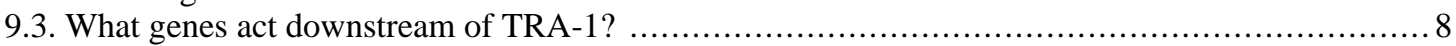

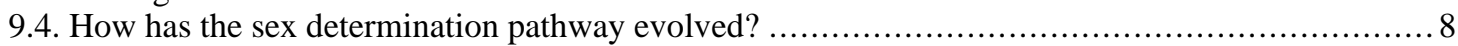

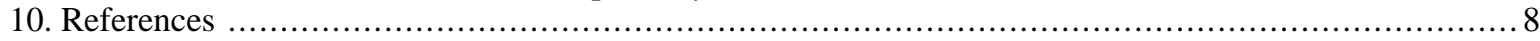

\begin{abstract}
C. elegans occurs in two natural sexes, the XX hermaphrodite and the XO male, which differ extensively in anatomy, physiology, and behavior. All somatic differences between the sexes result from the differential activity of a "global" sex determination regulatory pathway. This pathway also controls $X$ chromosome dosage compensation, which is coordinated with sex determination by the action of the three SDC proteins. The SDC proteins control somatic and germline sex by transcriptional repression of the her-1 gene. HER-1 is
\end{abstract}

\footnotetext{
${ }^{*}$ Edited by Barbara J. Meyer. Last revised February 8, 2005. Published February 10, 2006. This chapter should be cited as: Zarkower, D. Somatic sex determination (February 10, 2006), WormBook, ed. The C. elegans Research Community, WormBook, doi/10.1895/wormbook.1.84.1, http://www.wormbook.org.

Copyright: () 2006 David Zarkower. This is an open-access article distributed under the terms of the Creative Commons Attribution License, which permits unrestricted use, distribution, and reproduction in any medium, provided the original author and source are credited.

${ }^{\S}$ To whom correspondence should be addressed. E-mail: zarko001@umn.edu
} 
a secreted protein that controls a regulatory module consisting of a transmembrane receptor, TRA-2, three intracellular FEM proteins, and the zinc finger transcription factor TRA-1. The molecular workings of this regulatory module are still being elucidated. Similarity of TRA-2 to patched receptors and of TRA-1 to GLI proteins suggests that parts of the global pathway originally derived from a Hedgehog signaling pathway. TRA-1 controls all aspects of somatic sexual differentiation, presumably by regulating a variety of tissue- and cell-specific downstream targets, including the cell death regulator EGL-1 and the male sexual regulator MAB-3. Sex determination evolves rapidly, and conservation of sexual regulators between phyla has been elusive. An apparent exception involves DM domain proteins, including MAB-3, which control sexual differentiation in nematodes, arthropods, and vertebrates. Important issues needing more study include the detailed molecular mechanisms of the global pathway, the identities of additional sexual regulators acting in the global pathway and downstream of TRA-1, and the evolutionary history of the sex determination pathway. Recently developed genetic and genomic technologies and comparative studies in divergent species have begun to address these issues.

\section{A global sex determination pathway controls sexual dimorphism}

\subsection{Two highly dimorphic sexes}

The two natural sexes of $C$. elegans are the XX hermaphrodite and the XO male (Figure 1). Hermaphrodites are somatically female but can reproduce either by self-fertilization or by mating with males. Mating generates broods of half XX and half XO progeny. Self progeny mostly are XX, but about 1/500 are XO males, due to meiotic $\mathrm{X}$ chromosome nondisjunction, which ensures genetic exchange between individuals. The level of $\mathrm{X}$ chromosome nondisjunction, and hence the proportion of males in a population can be greatly increased by him (high incidence of males) mutations (Hodgkin et al., 1979). Because the two sexes differ in X chromosome dosage, a dosage compensation system has evolved to equalize expression of X-linked genes between XX and XO animals. This is accomplished by specifically reducing transcription of X-linked genes in XX animals (see X-chromosome dosage compensation). Sexual dimorphism is extensive in $C$. elegans, with most tissues and organs differing between the sexes in anatomy or physiology (Figure 1). Indeed, at least $40 \%$ of male and $30 \%$ of hermaphrodite cells are sexually specialized (Sulston and Horvitz, 1977). For further description of male- and hermaphrodite-specific development, see Male development and Hermaphrodite cell fate specification, respectively.

\section{XX hermaphrodite}
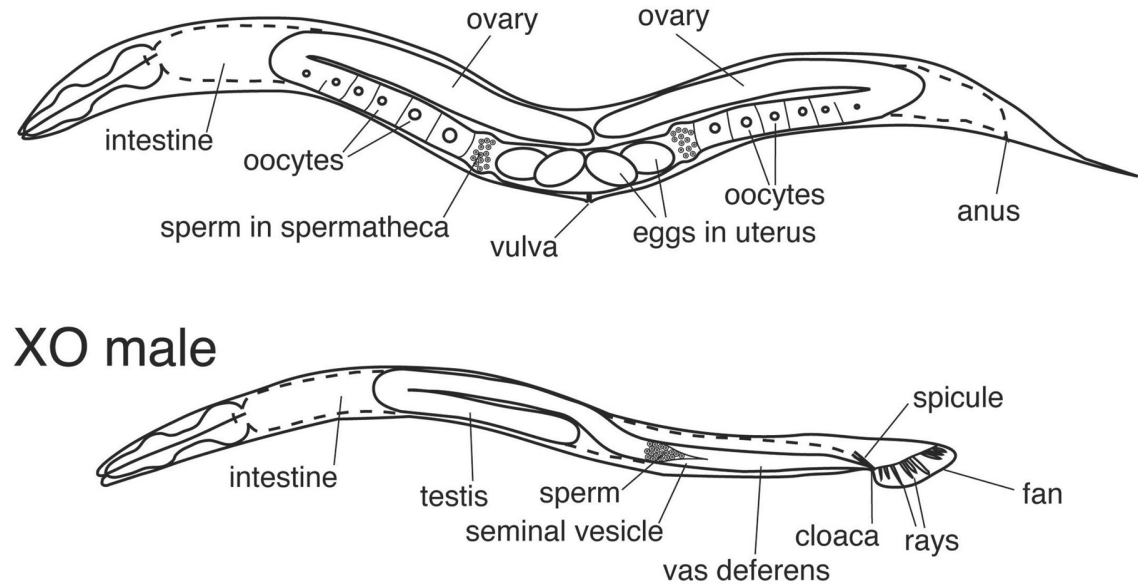

Figure 1. The two sexes of $\boldsymbol{C}$. elegans. The hermaphrodites and males differ strikingly in overall body size and structures such as the somatic gonad and tail. Many other tissues and organs are sexually dimorphic, notably the nervous system and musculature. More detailed description of sex-specific cells and structures can be found elsewhere in the Sex determination section.

\subsection{The global somatic sex determination pathway}

The sexual fates of all somatic cells are controlled by a regulatory pathway whose activity differs between the sexes (Figure 2). This regulatory pathway is often called a "global" sex determination pathway to distinguish it from more specialized regulatory pathways that control sexual differentiation of particular tissues and lineages. The global pathway also controls dosage compensation, the process that equalizes X-linked gene expression in the two 
sexes (see below). The global pathway was originally proposed on the basis of extensive genetic epistasis tests involving mutations affecting sex determination; it has been supported by subsequent molecular analysis (Hodgkin, 1987; Villeneuve and Meyer, 1990). In addition to the regulatory interactions shown in Figure 2, several minor interactions have been described, and these are thought to help reinforce the activity of the pathway in one sex or the other (Goodwin and Ellis, 2002). The same core regulatory pathway also controls sex determination in the germ line (see Vulval development). However, because hermaphrodites need to generate both oocytes and sperm, additional regulators are required in the germ line to temporarily reverse the sex determination decision, as described in Oocyte meiotic maturation and fertilization and Spermatogenesis .

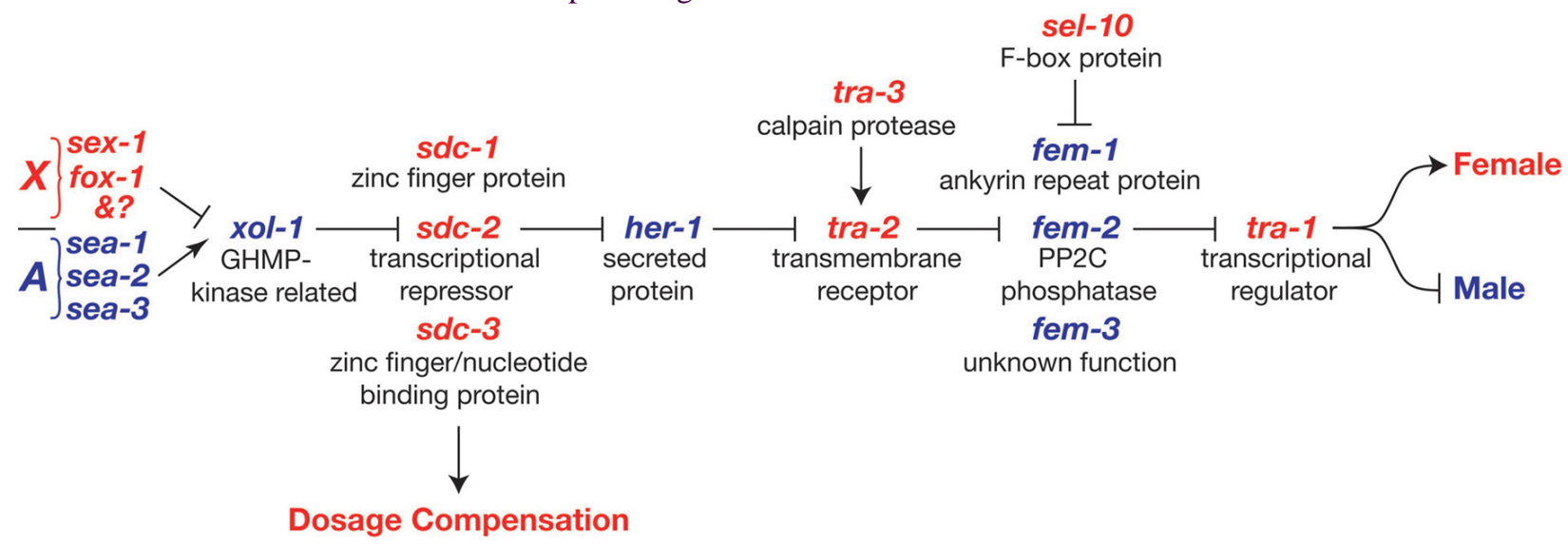

Figure 2. The global somatic sex determination pathway. Feminizing factors are shown in red and masculinizing factors in blue. Arrows represent positive regulatory interactions and bars represent negative interactions. As described in the text, additional minor regulatory interactions (not shown) may fine-tune the pathway. For more information on these genes see Wormbase.

The overall regulatory logic of the somatic sex determination scheme is seemingly straightforward. In essence, the number of $\mathrm{X}$ chromosomes controls a series of inhibitory interactions that ultimately sets the activity of the terminal regulator tra-1 (transformer 1). tra-1 then directs sexual differentiation throughout the soma (Hodgkin, 1987; Hodgkin and Brenner, 1977; Hunter and Wood, 1990).

If its purpose is to regulate tra- 1 activity, why does the pathway appear so needlessly baroque? Part of the explanation is that there are other functions and features, such as the need to coordinate dosage compensation with sex determination (see X-chromosome dosage compensation). Similarly, the fem genes promote spermatogenesis independently of their regulation of tra- 1 (Hodgkin, 1986). In addition, the pathway has regulatory interactions that enhance the plasticity and fidelity of the sex determination switch. One example is the ability of the pathway to reverse the sex determination decision in the XX germ line and allow both sperm and oocytes to form from a common stem cell pool. Another is the cell non-autonomous regulation of tra-2 by her-1, described below.

\section{The balance of X-linked and autosomal signal elements controls $\mathrm{xol}-1$}

The sex determination cascade is initiated in the early embryo by the ratio between the number of $\mathrm{X}$ chromosomes and sets of autosomes (X:A; Nigon, 1951). The X:A ratio determines the expression level of the

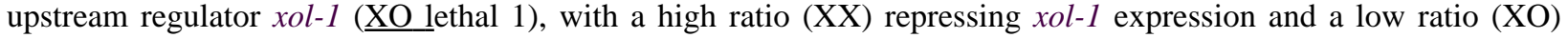
permitting high xol-1 expression. The activity of xol-1 then controls the rest of the sex determination pathway (Miller et al., 1988; Rhind et al., 1995). XOL-1 is structurally related to GHMP small molecule kinases, but it does not bind ATP and its regulatory activity is not yet understood (Luz et al., 2003).

The X:A ratio regulates the activity of xol-1 via the combined action of a set of "numerator" or X-signal elements on the X chromosome and "denominator," or autosomal, signal elements elsewhere in the genome. Genetic dissection of the X chromosome using duplications and deletions revealed that the X-signal is polygenic, involving at least four components (Akerib and Meyer, 1994). Further dissection and mutational analysis have identified two X-signal components, fox-1 and sex-1. FOX-1 is a putative RNA binding protein (Hodgkin et al., 1994; Nicoll et al., 1997; Skipper et al., 1999) that can post-transcriptionally repress a xol-1 reporter when overexpressed (Nicoll et al., 1997). SEX-1 is related to nuclear hormone receptors and represses xol-1 transcription, probably by direct binding to the xol-1 promoter (Carmi et al., 1998). 
The X-signal elements are opposed by autosomal signal elements. Three candidate genes were identified in a screen for suppressors of fox-1 sex-1 lethality. Two of these genes have been cloned and found to encode likely transcriptional regulators: sea- 1 encodes a T-box protein, and sea-2 a novel protein with zinc fingers and a metalloprotease domain (B. Meyer, pers. comm.; Powell et al., 2005).

The X:A signal system is exquisitely sensitive: although normally required to distinguish between ratios of 0.5 (XO) and 1.0 (XX), it can reliably discriminate a ratio of 0.67 from one of 0.75 (Madl and Herman, 1979).

\section{Sex determination and dosage compensation are coordinately regulated}

\subsection{The SDC proteins connect sex determination and dosage compensation}

The global sex determination pathway can be divided into two segments (Figure 2). The first segment (X:A signal to $s d c$ genes) coordinately controls both sex determination and dosage compensation, ensuring that these processes always occur in the same mode. The segment from her-1 onward is dedicated to sex determination.

The three SDC (s ex determination and dosage compensation defective) proteins link the gene-specific regulation of her-1 that controls sex determination with the chromosome-wide process of dosage compensation. The SDC proteins are components of a large protein complex that localizes to the $\mathrm{X}$ chromosomes of hermaphrodites early in embryogenesis and reduces their transcription by one-half (reviewed by Meyer, 2000; see X-chromosome dosage compensation).Components of the dosage compensation complex including the SDC proteins also control sex determination by binding to the promoter of her- 1 and repressing its transcription in $\mathrm{XX}$ animals to one-twentieth that of XO animals (her = hermaphroditization of XO; Chu et al., 2002; Dawes et al., 1999; Trent et al., 1991).

\subsection{SDC proteins and repression of her-1}

All three SDC proteins function both in repression of her-1 and in dosage compensation. However, there are clear indications that these processes are mechanistically distinct. First, the two complexes have different compositions. In particular, DPY-21 localizes to X but not to her-1 (Yonker and Meyer, 2003). There also are differences in how the complexes recognize their targets. SDC-2 plays a key role in X chromosome recognition, whereas SDC-3 is more important for her-1 recognition (Yonker and Meyer, 2003). The magnitude of transcriptional repression is much greater for her-l regulation than for dosage compensation of X-linked genes (twenty-fold versus two-fold, respectively; Dawes et al., 1999). Finally, the two activities of SDC-3 are genetically separable, with the ATP binding motif of SDC-3 required for regulation of her-1 and the zinc fingers required for dosage compensation (Klein and Meyer, 1993).

SDC-2 is expressed only in hermaphrodites, as a result of male-specific repression by XOL-1, and this gives the SDC complex sex-specificity (Dawes et al., 1999). Several potential SDC binding elements have been identified in her-1. Two of these contain a $15 \mathrm{bp}$ sequence not found on X; binding of SDC complexes to this element may mediate formation of a sex determination-specific complex (Chu et al., 2002). Two dominant gain-of-function alleles of her- 1 have been shown to alter promoter sequences and result in constitutive her- 1 expression (Perry et al., 1994). These mutations interfere with binding and regulation by the SDC complex (Chu et al., 2002).

\section{HER-1 and TRA-2 provide cell non-autonomous control of sexual fate}

\subsection{HER-1 inactivates TRA-2}

her-1 controls the segment of the pathway that is dedicated to sex determination. HER-1 is a small secreted protein and promotes male development in a cell non-autonomous manner, by inhibiting the function of the transmembrane protein TRA-2A (Hunter and Wood, 1992; Perry et al., 1993). A model illustrating likely molecular interactions between the sex-determining proteins from HER-1 to TRA-1 is shown in Figure 3. 


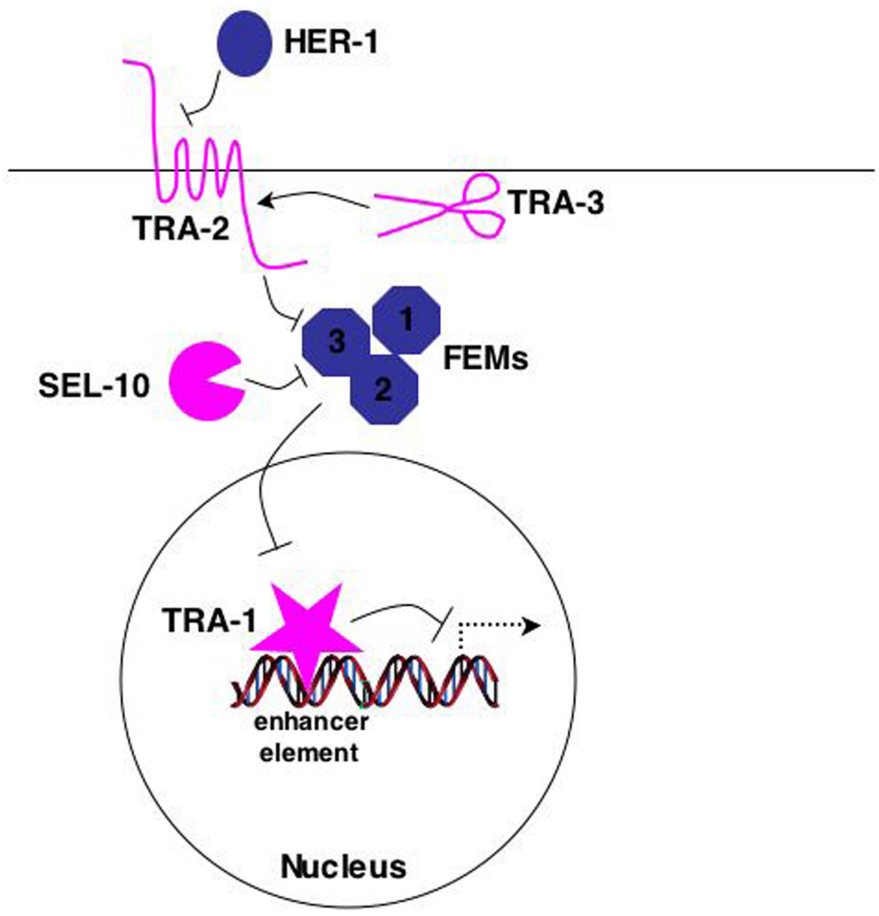

Figure 3. Molecular model of sex determination. Diagram illustrates likely relationships between sex determining proteins from HER-1 to the terminal global regulator TRA-1. Masculinizing proteins are blue, and feminizing proteins are pink. HER-1 is present only in XO males due to XX-specific transcriptional repression by the SDC proteins. In XO animals HER-1 binds the transmembrane receptor TRA-2A, blocking the ability of an intracellular domain of TRA-2A to inhibit FEM activity, and consequently the FEM proteins can inhibit TRA-1A. The TRA-3 protease may cleave TRA-2A to generate a fragment, TRA-2ic, with stronger feminizing activity. In XX animals active TRA-2A or TRA-2ic binds and inhibits FEM-3. As FEM-3 can bind FEM-2, this regulation may inhibit or sequester both proteins. The FEM proteins are targeted for proteasomal degradation by the F box protein SEL-10. When active (in XO animals) the FEM proteins somehow inhibit the activity of the transcriptional repressor TRA-1A. Active TRA-1A in XX animals binds DNA and blocks transcription driven by nearby enhancer elements in genes including mab-3, egl-1 and probably ceh-30, thereby establishing sexually dimorphic expression of specific genes in specific cell types. A number of molecular details remain poorly understood. In particular, it is not yet clear how TRA-2A inhibits the FEM proteins or how the FEM proteins inhibit TRA-1A.

There is compelling evidence for direct HER-1/TRA-2A binding: TRA-2A expression is necessary and sufficient to confer HER-1 binding to cultured cells, and the probable interaction interfaces of HER-1 and TRA-2A have been identified by a combination of genetic and structural studies (Hamaoka et al., 2004; Kuwabara, 1996). Having a cell non-autonomous step in the sex determination pathway has been suggested to help avoid errors by coordinating the sexual fates of cells. With a largely fixed cell lineage, C. elegans is limited in its ability to repair errors in cell fate specification. Secreted HER-1 also allows somatic control of germline sexual fate (Hunter and Wood, 1992).

tra-2 also is regulated by translational repression. This is of particular importance in the germ line (see Vulval development), but also is likely to affect TRA-2 expression in the soma. Disruption of elements in the 3' UTR of tra-2 can cause weak dominant feminization of the male soma and increased translation of reporters (Doniach, 1986; Goodwin et al.,1993). A candidate to mediate repression via the tra-2 3' UTR is the essential gene laf-1 (Goodwin et al., 1997).

\subsection{TRA-2 inactivates the FEM proteins}

The three FEM proteins ( $\mathrm{fem}=$ feminization) are a diverse group whose biochemistry is still largely unclear. FEM-1 has ankyrin repeats, but otherwise no obvious conserved motifs, FEM-2 is a serine/threonine protein phosphatase, and FEM-3 is novel (Ahringer et al., 1992; Chin-Sang and Spence, 1996; Pilgrim et al., 1995; Spence et al., 1990). All three are required for male development and, based on genetic epistasis tests, the appear to act between tra-2 and tra-1 to control somatic sex (Hodgkin, 1986). TRA-2A inhibits the FEM proteins in hermaphrodites, regulation that is prevented in males by HER-1. Regulation of the fem genes is not transcriptional, as they show similar expression levels in both sexes (Ahringer et al., 1992; Gaudet et al., 1996; Pilgrim et al., 1995). Instead regulation is likely to involve protein/protein interactions: in vitro and yeast two-hybrid interactions have been demonstrated between TRA-2A and FEM-3 (Mehra et al., 1999) and between FEM-3 and FEM-2 (Chin-Sang and Spence, 1996). Consequently, a simple model is that association of HER-1 with an extracellular domain of 
TRA-2A blocks the ability of an intracellular domain of TRA-2A to associate with and inhibit FEM-3 and FEM-2. How these interactions affect FEM protein function, whether the three FEM proteins form a complex in vivo, and what substrate FEM-2 dephosphorylates remain to be determined.

TRA-2A function may be enhanced by TRA-3, a calcium-dependent protease that can cleave TRA-2A in vitro to produce a peptide (TRA-2ic) that is predicted from transgenic experiments to have feminizing activity (Barnes and Hodgkin, 1996; Sokol and Kuwabara, 2000). Another negative regulator of the FEM proteins in hermaphrodites is SEL-10, one of a large family of F-box proteins. SEL-10 has weak feminizing activity in vivo, coimmunoprecipitates all three FEM proteins from transfected cells, and appears to target FEM-1 and FEM-3 for proteasomal degradation (Jager et al., 2004).

\section{High versus low tra-1 activity determines somatic cell sexual fates}

\subsection{TRA-1 is the nematode GLI protein}

The global sex determination pathway appears to act entirely though the terminal regulator tra-1. Active tra-1 promotes hermaphrodite development and prevents male development (Hodgkin, 1983; Hodgkin, 1987). tra-1 expresses two mRNAs encoding proteins with zinc fingers (Zarkower and Hodgkin, 1992). The larger transcript encodes TRA-1A, with five zinc fingers, and the smaller RNA encodes TRA-1B, which contains only the amino terminus and first two zinc fingers. It is unknown whether both proteins contribute to tra- 1 activity, but TRA-1A binds DNA in vitro, while TRA-1B does not (Zarkower and Hodgkin, 1993).

The zinc fingers of TRA-1 are highly similar to those of the Drosophila $\mathrm{Ci}$ and vertebrate GLI proteins, transcription factors regulated by Hedgehog signaling via the Patched and Smoothened co-receptors (Zarkower and Hodgkin, 1992). Although C. elegans lacks obvious Hedgehog or Smoothened homologs, it does have a number of Patched-related proteins, including TRA-2A (Kuwabara et al., 2000). This suggests that part of the global sex determination pathway originally derived from a Hedgehog signaling pathway.

\section{2. tra-1 has distinct functions in sex determination and gonadogenesis}

tra-l(null) $\mathrm{XX}$ animals are transformed into pseudomales that can be fertile, so robust male development is possible in the absence of tra- 1 function. However, these tra-l pseudomales frequently have small and disorganized somatic gonads, indicating that some tra-1 activity is required for development of the male somatic gonad (Hodgkin, 1987; Schedl et al., 1989). The gonadal defects stem at least in part from roles in the organization and proliferation of the gonadal primordium that are distinct from the sex determination function of tra- 1 .

tra- 1 controls gonadal development in concert with at least two other factors. During embryogenesis tra- 1 and ehn-3 together regulate formation of the somatic gonadal primordium (Mathies et al., 2004), and after hatching, tra-l and $f k h-6$ redundantly control gonadal cell proliferation (Chang et al., 2004).

\subsection{Regulation of tra-1 activity}

How tra- 1 activity is controlled is still poorly understood. Many strong gain-of-function mutations have been isolated (Hodgkin, 1987). All affect a short protein sequence common to TRA-1A and TRA-1B (the "gain-of-function domain"), suggesting that regulation of TRA-1 is primarily post-translational (de Bono et al., 1995). As tra-1 activity is controlled by the three FEM proteins, an attractive model is that a FEM protein inhibits the activity of TRA-1 via interaction with the gain-of-function domain. Regulation may involve the localization, modification, or degradation of TRA-1 (or a combination of these, as sex-specific differences in processing and nuclear accumulation of the TRA-1 protein(s) have been observed; Segal et al., 2001; A. Spence, pers. comm.).

\section{TRA-1 links global and tissue-specific sexual regulation}

TRA-1 directs sexually dimorphic development at the cellular level, with diverse consequences in different cell types. Direct transcriptional regulation by TRA-1 in somatic cells has thus far been shown for mab-3 (Yi et al., 2000) and egl-1 (Conradt and Horvitz, 1999). Both genes are transcriptionally repressed by TRA-1 in specific hermaphrodite cell types in order to prevent male differentiation. TRA-1 represses $m a b-3$ transcription in the XX intestine, thereby preventing MAB-3 from repressing yolk protein transcription in hermaphrodites (Yi and Zarkower, 1999; Yi et al., 2000). egl-1 is a global regulator of programmed cell death (Conradt and Horvitz, 1998); however a TRA- 1 binding site is found nearly $6 \mathrm{~kb}$ downstream of the egl- 1 coding region. Disruption of this site in 
egl-1 gain-of-function mutants results in ectopic egl-1 transcription in the HSN neurons causes the death of these cells (Conradt and Horvitz,1999). TRA-1 likely represses the homeobox gene ceh-30 to control sex-specific death of the four CEM neurons: ceh-30 is required for CEM survival in males; and mutations in a conserved TRA-1 consensus binding site near ceh-30 cause ectopic CEM survival in XX animals (H. Schwartz and H.R. Horvitz, pers. comm.).

From the limited data available, a picture emerges in which TRA-1 is expressed widely but exerts highly selective effects on target gene expression in particular cell types. This specificity may arise from short-range transcriptional repression, in which TRA-1 binding to DNA only blocks the activity of cis elements within a limited distance (Yi et al., 2000). By repressing some enhancer elements in a target gene without affecting others, a globally-expressed regulator like TRA-1 can control expression of each target gene selectively in particular cells or tissues. It has been suggested that short-range repression facilitates "sampling" of new target genes by the global regulator during evolution and thereby provides superior evolutionary flexibility (Cai et al., 1996; Gray et al., 1994; Zarkower, 2001).

\section{Downstream sexual regulators: the interface between sex determination and sexual differentiation}

The critical role of TRA-1 in establishing sexual dimorphism and its function as a likely transcriptional regulator have been known for some time. Despite this, surprisingly little is known of the genes that function directly downstream of TRA-1 in specific cell lineages, tissues, and organs to generate sexual dimorphism. For example, tra-1 controls whether the posterior seam cells V5 and V6 generate male V rays or hermaphrodite lateral hypodermis (see Male development), but no TRA-1 target has been identified in this lineage. Regulation by TRA-1 of $m a b-3$ and $e g l-1$ accounts for only a small proportion of sexual dimorphism; many additional direct targets likely await discovery.

The establishment of sexual dimorphism can be roughly divided into two steps, first the sex determination decision, and second the execution of sexual differentiation. In general, mutations that abrogate sex determination cause sex reversal, and this is true of all the genes in the global pathway. By contrast, mutations in regulators of sexual differentiation cause defects in this process, but not sex reversal. TRA-1 and its targets are at the interface between these processes. mab-3 illustrates that the distinction between regulators of sex determination and sexual differentiation can be hazy. mab-3 mutant males have a feminized intestine that produces yolk, but the $\mathrm{V}$ ray lineages in the mab-3 male tail are defective rather than feminized (Shen and Hodgkin, 1988). Another gene at this interface is the gonadal regulator $f k h-6$, which has a sex-determining function in the early male somatic gonad, and a differentiation role later in the hermaphrodite gonad (Chang et al., 2004).

\section{Some aspects of sex determination may be evolutionarily conserved}

Primary sex-determining mechanisms are extremely varied and evolve rapidly (see The evolution of nematode sex determination). The lability of sex determination is clearly demonstrated by the ease with which the process can be brought under the control of different genes in the pathway. Hodgkin has shown that any of seven autosomal sex determination genes can be genetically manipulated to become the primary determinant of sex, and that any of the five autosomes can thereby become a sex chromosome (Hodgkin, 2002). Given the facility with which new sex determination pathways can be created in the laboratory, they would be expected to be highly diverse in nature. This is the case: none of the sex-determining genes in Figure 2 has been found to have a homolog playing a similar role outside the nematode phylum.

So far the best candidates for conserved sexual regulators are downstream genes related to Drosophila doublesex. These are termed DM domain (doublesex and mab-3 related) genes, after the conserved DNA binding motif they share (Erdman and Burtis, 1993; Raymond et al., 1998; Zhu et al., 2000). In C. elegans these include $m a b-3$ and $m a b-23$, both of which regulate multiple aspects of male differentiation and behavior (Lints and Emmons, 2002; Shen and Hodgkin, 1988; Yi et al., 2000). Genes encoding DM domain proteins have been shown to regulate sexual development in mammals (Raymond et al., 2000) and fish (Matsuda et al., 2002; Nanda et al., 2002), and are likely, based on sexually dimorphic expression and sex-linkage, to play similar roles in other vertebrates with different sex determination mechanisms (Zarkower, 2001). Thus it appears that at least some downstream sexual regulators have an ancient involvement in sexual dimorphism that is more stable than that of the upstream primary sex determination pathway. While $m a b-3$ and $m a b-23$ primarily function in sexual differentiation rather than sex determination, comparison with Drosophila and vertebrate homologs suggests that the ancestral role of 
these genes may have been in sex determination. As more sexual regulators downstream of TRA-1 are identified, other conserved factors may be found.

\section{Open questions}

Much progress has been made in understanding the regulation of somatic sex determination in C. elegans, but new questions have been raised and some old ones remain unanswered. Questions needing more experimental attention can be divided into four categories:

\subsection{Molecular mechanisms of the global pathway}

How the cascade of inhibitory interactions that converts X chromosome dosage into TRA- 1 activity functions is known in outline, but not in great detail. Do the $\mathrm{X}$ and autosomal signal elements antagonize one another directly or indirectly? How does the interaction of TRA-2A with FEM-3 inactivate the FEM proteins, and how does HER-1 binding to TRA-2A prevent this inactivation? How do the FEM proteins repress tra-l activity? FEM-2 is a phosphatase, so does regulation of TRA-1 involve sex-differential phosphorylation, and if so what is the kinase? How is TRA-1 processed to generate sex-specific peptides, and what are their activities?

\subsection{Other regulators}

Most of known sex determining genes were found in genetic screens for defects in sexual differentiation. These screens have probably identified all of the genes whose loss of function phenotype is severe sex reversal. However, although many of these screens were conducted in sensitized genetic backgrounds, other regulators must have been missed, particularly essential genes and those that act redundantly. Two lines of evidence make it clear that such genes exist. First, there are biochemical activities unaccounted for, such as the putative kinase whose phosphorylation is reversed by FEM-2. Second, there is genetic evidence for additional regulators. As an example, mutating xol-1 enhances the masculinization of XX tra-(null) mutants, suggesting that another regulator(s) acts downstream of xol-1 and in parallel with tra-2 to promote tra- 1 activity (Hodgkin and Brenner, 1977; Miller et al., 1988). Focused molecular screens should allow the identification of such regulatory molecules.

\subsection{What genes act downstream of TRA-1?}

TRA-1 activity directs alternative cell fates throughout the soma. This involves transcriptional repression of dedicated sexual regulators ( $m a b-3)$ and of more general cellular factors (egl-1), and can control the physiology of entire organs like the intestine or the fates of individual cells. Is $m a b-3$ or $e g l-1$ the more typical TRA-1 target? Does TRA-1 act exclusively as a transcriptional repressor or might it also activate transcription? Much work remains to find genes that act downstream of TRA-1 in other tissues. This will aid in understanding how sexual dimorphism is established in different cell types and how sexual regulation interacts with spatial and temporal regulation during development. The improved availability of reporter genes marking sexually dimorphic tissues and new techniques for global analysis of gene expression and function should accelerate progress.

\subsection{How has the sex determination pathway evolved?}

Evolution of sex determination pathways is covered in detail in The evolution of nematode sex determination. The $C$. elegans sex determination pathway has been proposed to have arisen from a "bottom up" accretion of negative regulators during evolution (Wilkins, 1995). Genetic investigations of somatic sex determination in other nematodes have begun, and these, along with comparative molecular studies, are certain to be informative. As mentioned earlier, the pathway from her-1 to tra-l appears to derive from a hedgehog signaling pathway which might have been co-opted in one step; comparative studies should clarify this question. As more divergent species are studied, it also will become clearer which parts of the C. elegans pathway are ancient and which are more recently recruited. In particular, it will be important to test suggestions that DM domain genes like mab-3 and $m a b-23$ are descended from very ancient metazoan sex-determining genes.

\section{References}

Ahringer, J., Rosenquist, T.A., Lawson, D.N., and Kimble, J. (1992). The Caenorhabditis elegans sex determining gene fem-3 is regulated post-transcriptionally. EMBO J. 11, 2303-2310. Abstract 
Akerib, C.C., and Meyer, B.J. (1994). Identification of X chromosome regions in Caenorhabditis elegans that contain sex-determination signal elements. Genetics 138, 1105-1125. Abstract

Barnes, T.M., and Hodgkin, J. (1996). The tra-3 sex determination gene of Caenorhabditis elegans encodes a member of the calpain regulatory protease family. EMBO J. 15, 4477-4484. Abstract

Cai, H.N., Arnosti, D.N., and Levine, M. (1996). Long-range repression in the Drosophila embryo. Proc. Natl. Acad. Sci. USA 93, 9309-9314. Abstract Article

Carmi, I., Kopczynski, J.B., and Meyer, B.J. (1998). The nuclear hormone receptor SEX-1 is an X-chromosome signal that determines nematode sex. Nature 396, 168-173. Abstract Article

Chang, W., Tilmann, C., Thoemke, K., Markussen, F.H., Mathies, L.D., Kimble, J., and Zarkower, D. (2004). A forkhead protein controls sexual identity of the C. elegans male somatic gonad. Development 131, 1425-1436. Abstract Article

Chin-Sang, I.D., and Spence, A.M. (1996). Caenorhabditis elegans sex-determining protein FEM-2 is a protein phosphatase that promotes male development and interacts directly with FEM-3. Genes Dev. 10, 2314-2325. Abstract

Chu, D.S., Dawes, H.E., Lieb, J.D., Chan, R.C., Kuo, A.F., and Meyer, B.J. (2002). A molecular link between gene-specific and chromosome-wide transcriptional repression. Genes Dev. 16, 796-805. Abstract Article

Conradt, B., and Horvitz, H.R. (1998). The C. elegans protein EGL-1 is required for programmed cell death and interacts with the Bcl-2-like protein CED-9. Cell 93, 519-529. Abstract Article

Conradt, B., and Horvitz, H.R. (1999). The TRA-1A sex determination protein of C. elegans regulates sexually dimorphic cell deaths by repressing the egl-1 cell death activator gene. Cell 98, 317-327. Abstract Article

Dawes, H.E., Berlin, D.S., Lapidus, D.M., Nusbaum, C., Davis, T.L., and Meyer, B.J. (1999). Dosage compensation proteins targeted to $\mathrm{X}$ chromosomes by a determinant of hermaphrodite fate. Science 284, 1800-1804. Abstract Article

de Bono, M., Zarkower, D., and Hodgkin, J. (1995). Dominant feminizing mutations implicate protein-protein interactions as the main mode of regulation of the nematode sex-determining gene tra-1. Genes Dev. 9, 155-167. Abstract

Doniach, T. (1986). Activity of the sex-determining gene tra-2 is modulated to allow spermatogenesis in the $C$. elegans hermaphrodite. Genetics 114, 53-76. Abstract

Erdman, S.E., and Burtis, K.C. (1993). The Drosophila doublesex proteins share a novel zinc finger related DNA binding domain. EMBO J. 12, 527-535. Abstract

Gaudet, J., VanderElst, I., and Spence, A.M. (1996). Post-transcriptional regulation of sex determination in Caenorhabditis elegans: widespread expression of the sex-determining gene fem-1 in both sexes. Mol. Biol. Cell 7, 1107-1121. Abstract

Goodwin, E.B., and Ellis, R.E. (2002). Turning clustering loops: sex determination in Caenorhabditis elegans. Curr. Biol. 12, R111-120. Abstract Article

Goodwin, E.B., Hofstra, K., Hurney, C.A., Mango, S., and Kimble, J. (1997). A genetic pathway for regulation of tra-2 translation. Development 124, 749-758. Abstract

Goodwin, E.B., Okkema, P.G., Evans, T.C., and Kimble, J. (1993). Translational regulation of tra-2 by its 3' untranslated region controls sexual identity in C. elegans. Cell 75, 329-339. Abstract Article

Gray, S., Szymanski, P., and Levine, M. (1994). Short-range repression permits multiple enhancers to function autonomously within a complex promoter. Genes Dev. 8, 1829-1838. Abstract 
Hamaoka, B.Y., Dann, C.E., 3rd, Geisbrecht, B.V., and Leahy, D.J. (2004). Crystal structure of Caenorhabditis elegans HER-1 and characterization of the interaction between HER-1 and TRA-2A. Proc. Natl. Acad. Sci. USA 101, 11673-11678. Abstract Article

Hodgkin, J. (1983). Two types of sex determination in a nematode. Nature 304, 267-268. Abstract Article

Hodgkin, J. (1986). Sex determination in the nematode C. elegans: analysis of tra-3 suppressors and characterization of fem genes. Genetics 114, 15-52. Abstract

Hodgkin, J. (1987). A genetic analysis of the sex-determining gene, tra-1, in the nematode Caenorhabditis elegans. Genes Dev. 1, 731-745. Abstract Article

Hodgkin, J. (1987). Sex determination and dosage compensation in Caenorhabditis elegans. Annu. Rev. Genet. 21, 133-154. Abstract Article

Hodgkin, J. (2002). Exploring the envelope. Systematic alteration in the sex-determination system of the nematode Caenorhabditis elegans. Genetics 162, 767-780. Abstract

Hodgkin, J., Horvitz, H.R., and Brenner, S. (1979). Nondisjunction mutants of the nematode C. elegans. Genetics 91, 67-94.

Hodgkin, J., Zellan, J.D., and Albertson, D.G. (1994). Identification of a candidate primary sex determination locus, fox-1, on the X chromosome of Caenorhabditis elegans. Development 120, 3681-3689. Abstract

Hodgkin, J.A., and Brenner, S. (1977). Mutations causing transformation of sexual phenotype in the nematode Caenorhabditis elegans. Genetics 86, 275-287. Abstract

Hunter, C.P., and Wood, W.B. (1990). The tra-1 gene determines sexual phenotype cell-autonomously in $C$. elegans. Cell 63, 1193-1204. Abstract Article

Hunter, C.P., and Wood, W.B. (1992). Evidence from mosaic analysis of the masculinizing gene her-1 for cell interactions in C. elegans sex determination. Nature 355, 551-555. Abstract Article

Jager, S., Schwartz, H.T., Horvitz, H.R., and Conradt, B. (2004). The Caenorhabditis elegans F-box protein SEL-10 promotes female development and may target FEM-1 and FEM-3 for degradation by the proteasome. Proc. Natl. Acad. Sci. USA 101, 12549-12554. Abstract Article

Klein, R.D., and Meyer, B.J. (1993). Independent domains of the Sdc-3 protein control sex determination and dosage compensation in C. elegans. Cell 72, 349-364. Abstract Article

Kuwabara, P.E. (1996). A novel regulatory mutation in the C. elegans sex determination gene tra-2 defines a candidate ligand/receptor interaction site. Development 122, 2089-2098. Abstract

Kuwabara, P.E., Lee, M.H., Schedl, T., and Jefferis, G.S. (2000). A C. elegans patched gene, ptc-1, functions in germ-line cytokinesis. Genes Dev. 14, 1933-1944. Abstract

Lints, R., and Emmons, S.W. (2002). Regulation of sex-specific differentiation and mating behavior in C. elegans by a new member of the DM domain transcription factor family. Genes Dev. 16, 2390-2402. Abstract Article

Luz, J.G., Hassig, C.A., Pickle, C., Godzik, A., Meyer, B.J., and Wilson, I.A. (2003). XOL-1, primary determinant of sexual fate in C. elegans, is a GHMP kinase family member and a structural prototype for a class of developmental regulators. Genes Dev. 17, 977-990. Abstract Article

Madl, J.E., and Herman, R.K. (1979). Polyploids and sex determination in Caenorhabditis elegans. Genetics 93, 393-402. Abstract

Mathies, L.D., Schvarzstein, M., Morphy, K.M., Blelloch, R., Spence, A.M., and Kimble, J. (2004). TRA-1/GLI controls development of somatic gonadal precursors in C. elegans. Development 131, 4333-4343. Abstract Article 
Matsuda, M., Nagahama, Y., Shinomiya, A., Sato, T., Matsuda, C., Kobayashi, T., Morrey, C.E., Shibata, N., Asakawa, S., Shimizu, N., et al. (2002). DMY is a Y-specific DM-domain gene required for male development in the medaka fish. Nature 417, 559-563. Abstract Article

Mehra, A., Gaudet, J., Heck, L., Kuwabara, P.E., and Spence, A.M. (1999). Negative regulation of male development in Caenorhabditis elegans by a protein-protein interaction between TRA-2A and FEM-3. Genes Dev. 13, 1453-1463. Abstract

Meyer, B.J. (2000). Sex in the worm: counting and compensating X-chromosome dose. Trends Genet 16, 247-253. Abstract Article

Miller, L.M., Plenefisch, J.D., Casson, L.P., and Meyer, B.J. (1988). xol-1: a gene that controls the male modes of both sex determination and X chromosome dosage compensation in C. elegans. Cell 55, 167-183. Abstract Article

Nanda, I., Kondo, M., Hornung, U., Asakawa, S., Winkler, C., Shimizu, A., Shan, Z., Haaf, T., Shimizu, N., Shima, A., et al. (2002). A duplicated copy of DMRT1 in the sex-determining region of the Y chromosome of the medaka, Oryzias latipes. Proc. Natl. Acad. Sci. USA 99, 11778-11783. Abstract Article

Nicoll, M., Akerib, C.C., and Meyer, B.J. (1997). X-chromosome-counting mechanisms that determine nematode sex. Nature 388, 200-204. Abstract Article

Nigon, V. (1951). Polyploidie experimentale chez un Nematode libre, Rhabditis elegans. Maupas. Bull. Biol. Fr. Belg. 85, 187-225.

Perry, M.D., Li, W., Trent, C., Robertson, B., Fire, A., Hageman, J.M., and Wood, W.B. (1993). Molecular characterization of the her-1 gene suggests a direct role in cell signaling during Caenorhabditis elegans sex determination. Genes Dev. 7, 216-228. Abstract

Perry, M.D., Trent, C., Robertson, B., Chamblin, C., and Wood, W.B. (1994). Sequenced alleles of the Caenorhabditis elegans sex-determining gene her-1 include a novel class of conditional promoter mutations. Genetics 138, 317-327. Abstract

Pilgrim, D., McGregor, A., Jackle, P., Johnson, T., and Hansen, D. (1995). The C. elegans sex-determining gene fem-2 encodes a putative protein phosphatase. Mol. Biol. Cell. 6, 1159-1171. Abstract

Powell, J.R., Jow, M.M., and Meyer, B.J. (2005). The T-box transcription factor SEA-1 is an autosomal element of the X:A signal that determines C. elegans sex. Dev. Cell. 9, 339-349. Abstract Article

Raymond, C.S., Murphy, M.W., O'Sullivan, M.G., Bardwell, V.J., and Zarkower, D. (2000). Dmrt1, a gene related to worm and fly sexual regulators, is required for mammalian testis differentiation. Genes Dev. 14, 2587-2595. Abstract Article

Raymond, C.S., Shamu, C.E., Shen, M.M., Seifert, K.J., Hirsch, B., Hodgkin, J., and Zarkower, D. (1998). Evidence for evolutionary conservation of sex-determining genes. Nature 391, 691-695. Abstract Article

Rhind, N.R., Miller, L.M., Kopczynski, J.B., and Meyer, B.J. (1995). xol-1 acts as an early switch in the C. elegans male/hermaphrodite decision. Cell 80, 71-82. Abstract Article

Schedl, T., Graham, P.L., Barton, M.K., and Kimble, J. (1989). Analysis of the role of tra-1 in germline sex determination in the nematode Caenorhabditis elegans. Genetics 123, 755-769. Abstract

Segal, S.P., Graves, L.E., Verheyden, J., and Goodwin, E.B. (2001). RNA-Regulated TRA-1 nuclear export controls sexual fate. Dev. Cell 1, 539-551. Abstract Article

Shen, M.M., and Hodgkin, J. (1988). mab-3, a gene required for sex-specific yolk protein expression and a male-specific lineage in C. elegans. Cell 54, 1019-1031. Abstract Article

Skipper, M., Milne, C.A., and Hodgkin, J. (1999). Genetic and molecular analysis of fox-1, a numerator element involved in Caenorhabditis elegans primary sex determination. Genetics 151,617-631. Abstract 
Sokol, S.B., and Kuwabara, P.E. (2000). Proteolysis in Caenorhabditis elegans sex determination: cleavage of TRA-2A by TRA-3. Genes Dev. 14, 901-906. Abstract

Spence, A.M., Coulson, A., and Hodgkin, J. (1990). The product of fem-1, a nematode sex-determining gene, contains a motif found in cell cycle control proteins and receptors for cell-cell interactions. Cell 60, 981-990. Abstract Article

Sulston, J.E., and Horvitz, H.R. (1977). Post-embryonic cell lineages of the nematode, Caenorhabditis elegans. Dev. Biol. 56, 110-156. Abstract Article

Trent, C., Purnell, B., Gavinski, S., Hageman, J., Chamblin, C., and Wood, W.B. (1991). Sex-specific transcriptional regulation of the C. elegans sex-determining gene her-1. Mech. Dev. 34, 43-55. Abstract Article

Villeneuve, A.M., and Meyer, B.J. (1990). The regulatory hierarchy controlling sex determination and dosage compensation in Caenorhabditis elegans. Adv. Genet. 27, 117-188. Abstract

Wilkins, A.S. (1995). Moving up the hierarchy: a hypothesis on the evolution of a genetic sex determination pathway. Bioessays 17, 71-77. Abstract Article

Yi, W., Ross, J.M., and Zarkower, D. (2000). Mab-3 is a direct tra- 1 target gene regulating diverse aspects of $C$. elegans male sexual development and behavior. Development 127, 4469-4480. Abstract

Yi, W., and Zarkower, D. (1999). Similarity of DNA binding and transcriptional regulation by Caenorhabditis elegans MAB-3 and Drosophila melanogaster DSX suggests conservation of sex determining mechanisms. Development 126, 873-881. Abstract

Yonker, S.A., and Meyer, B.J. (2003). Recruitment of $C$. elegans dosage compensation proteins for gene-specific versus chromosome-wide repression. Development 130, 6519-6532. Abstract Article

Zarkower, D. (2001). Establishing sexual dimorphism: conservation amidst diversity? Nat. Rev. Genet. 2, 175-185. Abstract Article

Zarkower, D., and Hodgkin, J. (1992). Molecular analysis of the C. elegans sex-determining gene tra-1: a gene encoding two zinc finger proteins. Cell 70, 237-249. Abstract Article

Zarkower, D., and Hodgkin, J. (1993). Zinc fingers in sex determination: only one of the two C. elegans Tra-1 proteins binds DNA in vitro. Nucleic Acids Res. 21, 3691-3698. Abstract

Zhu, L., Wilken, J., Phillips, N.B., Narendra, U., Chan, G., Stratton, S.M., Kent, S.B., and Weiss, M.A. (2000). Sexual dimorphism in diverse metazoans is regulated by a novel class of intertwined zinc fingers. Genes Dev. 14, 1750-1764. Abstract Article

All WormBook content, except where otherwise noted, is licensed under a Creative Commons Attribution License. 